a life limiting illness. The death of a parent has long term implications for children's emotional, social and physical wellbeing (Cockle-Hearne, Reed, Todd et al., 2020). If a child isn't prepared for parental death or supported afterwards, they are more likely than their peers to have higher levels of referrals to psychiatric and specialist services and absence at school (Osborn, 2007; Niemelä, Paananen, Hakko et al., 2016). When death can be anticipated, healthcare providers have an opportunity to provide appropriate support that can reduce the impact of the loss.

Aim A survey was carried out to explore the experiences of hospital staff when supporting children whose parent or grandparent was dying. 67 staff members responded.

Results $84 \%$ of staff had not had any training in supporting children. Over 50\% lacked confidence in knowing who to signpost families to and many were unable to identify local organisations who could help. $76 \%$ of staff have been left feeling distressed after caring for a dying patient with young children or grandchildren. $85 \%$ of staff felt that a child bereavement counsellor would have made things better for the children. $79 \%$ think a child bereavement counsellor would have reduced stress for staff.

Conclusion This survey supported the concerns that children are often not provided with appropriate support when a parent has a terminal diagnosis and as such are faced with the risk of future harm. It is apparent from this review that children who experienced the death of a parent have been reliant on a workforce who lacked training and confidence in this area. This has meant that families may not have been supported to have honest and open conversations to prepare for the death. Our survey also highlighted the significant impact on staff of caring for dying patients with young children. In response to these findings the trust has collaborated with a local hospice to appoint a child bereavement counsellor to work alongside colleagues in the hospital. The counsellor will provide direct support to children as needed but will also aim to improve the confidence and skill of the ward staff when working with young families. In addition, there is a commitment to recognise the emotional impact on staff and to provide increased opportunity for reflection.

\section{P-26 PRECIOUS TIME: THERAPEUTIC ANTICIPATORY GRIEF RESOURCE FOR CHILDREN AND FAMILIES}

Lyndsey Stukalov-Stone. Heart of Kent Hospice, Maidstone, UK

\subsection{6/spcare-2021-Hospice.47}

Background Precious Time (for school age children, 5-11 years) is a beautifully written, illustrated and published children's book which focuses on supporting families facing anticipatory grief. The author, a palliative care social worker and counsellor identified the need to develop a therapeutic tool that supports both the child and family. 'Precious time' encourages the involvement of children in end-of-life discussions throughout the interactive book and helps families and professionals find the right words to ensure the child understands their loved one is going to die, what this means and how the family can support each other during this difficult time.
Aim The resource aims to ensure families have these discussions early, to feel confident and prepared. The author has observed that this will help children's formation of memories and encourage communication between family members - which will result in an improved end-of-life experience for the child, patient, and their family, and ensure the child's mental health, resilience and wellbeing is best supported.

Method This resource was developed through conversations with children who have experienced anticipatory grief. Frequently children told the author that they found out their loved one is dying by accident and without the significant adult's awareness or support. Children experienced anger, mistrust, frustration and anxiety. Young people said that this became embedded in their memory as a distressing significant moment. The author wrote the book with this need in mind, to promote and support clear and honest communication about death and end-of-life discussions with children.

Conclusion Families have reached out on social media platforms thanking the author for bringing this important subject to light. Every child deserves to feel informed, involved and supported when their loved one is facing the end of their life. 'Precious Time' leads the way in creating this clear approach to help support short and long-term positive outcomes for bereaved children. It is a book written and inspired directly by working with children and families, giving a unique insight into what children want to know when a loved one is dying.

\section{P-27 KITH AND KIN: SUPPORTING BEREAVED YOUNG PEOPLE IN KINSHIP CARE NETWORKS}

Janice Lee, Mary Mooney, Alex Mula. Ardgowan Hospice, Greenock, UK

\subsection{6/spcare-2021-Hospice. 48}

Background Ardgowan Hospice reflected on a report by Grandparents Plus (Wellard, Meakings, Farmer, et al., 2017) which noted that $38 \%$ of children in kinship care had already experienced the death of one or both parents. The foreword to this report advised that the report 'shone a light on a group of young people that has been invisible to policy makers and service providers.' The hospice recognised that this group of bereaved young people could be overlooked by services and that no service in our local area of Inverclyde offered services specific to the needs of bereaved children and young people who live in kinship care networks.

Aims To provide support to both formal and informal kinship families offering bereavement support, one-to-one and group sessions as well as delivering awareness raising sessions to key partners and established groups.

Methods We established a multi-agency working group incorporating Ardgowan Hospice, Barnardo's and the local authority Kinship team. This group highlighted a gap in service provision for change and loss.

We then met with the local kinship group, Family Ties, (a statutory social work- led support group for formal kinship carers) and ran loss and change sessions. The information gathered at these sessions helped us plan our interventions and meet the needs of this disadvantaged group.

Result One of the most successful elements of this project was the strong partnerships forged and the collaborative working 